\title{
Experimental Study on Nonlinear Seepage Characteristics and Particle Size Gradation Effect of Fractured Sandstones
}

\author{
Xuyang Shi, Wei Zhou (D), Qingxiang Cai ${ }^{D}$, and Xiang Lu \\ School of Mines, China University of Mining \& Technology, Xuzhou 221116, China \\ Correspondence should be addressed to Wei Zhou; loutian1982@126.com
}

Received 31 May 2018; Accepted 8 August 2018; Published 15 October 2018

Academic Editor: Yan Peng

Copyright ( $\odot 2018$ Xuyang Shi et al. This is an open access article distributed under the Creative Commons Attribution License, which permits unrestricted use, distribution, and reproduction in any medium, provided the original work is properly cited.

\begin{abstract}
Seepage mutation of fractured rock mass is one of the main inducements of dump slide and other disasters. Pore structure is a significant factor affecting the seepage characteristics of fractured rock mass, while particle size gradation has an important effect on the distribution of pore structure. Through the self-developed experimental system, the nonlinear seepage test on the fractured sandstones of the coalseam roof was conducted to investigate the influence of seepage pressure, porosity, and fractal dimension. Besides, the nonlinear seepage model was established by Barree-Conway theory. The results showed that, during the seepage process of fractured sandstone, there were significant nonlinear characteristics, which increased with the increase of the seepage pressure. With the increasing porosity, there was greater average pore size of fractured sandstone, stronger permeability, and weaker nonlinear seepage. The seepage characteristics approximated to that of Darcy model. However, with increasing grading fractal dimension, there were smaller average pore size of fractured sandstone, weaker permeability, and stronger nonlinear seepage. The seepage characteristics approximated to that of Forchheimer model.
\end{abstract}

\section{Introduction}

During the mine exploitation, local fractured rock mass structure was formed due to geological movement or mining activity, such as waste dump, fault fracture zone [1-4], collapse pillar [5], and caving zone [6]. Fractured rock mass is composed of rock particles with different particle sizes. It has a relatively developed pore structure with poor stability of the skeleton structure. Therefore, its permeability is usually several orders of magnitude greater than that of intact rock mass [6]. In the surrounding rock structure of coal mine roadway, fractured rock mass is the main area that causes seepage failure and water disasters, such as coal piping, water burst, and mud gushing [7]. In addition to mining engineering, filling materials of the dam foundation and roadbed are also fractured rock mass $[8,9]$ in the construction project, and there is also a series of hidden dangers of water inrush. Therefore, it is of great significance to clarify the seepage characteristics of fractured rock mass for the prevention and control of geological disasters caused by seepage.
At the earliest, Darcy constructed the linear flow equation to describe the seepage characteristics of sand, that is, the Darcy flow equation. Subsequently, a large number of experiments on fractured sandstones seepage of were carried out with various experimental methods [10-14]. With further research, it is found that the seepage behavior of fractured rock mass has obvious nonlinear characteristics, and the traditional linear equation cannot be used to characterize the nonlinear seepage behavior of fractured sandstones [15-19]. Forchheimer et al. believed that the factor that represents the inertial potential of fractured sandstones should be introduced in the nonlinear equation and established the second-order nonlinear flow rule for fractured sandstones. Later Scheidegger model and Ergun model was built on the basis of the Forchheimer model. However, these models still have the disadvantages of being overly ideal and containing empirical coefficients, which cannot be widely used. In 2004, Barree and Conway [20] proposed the Barree-Conway model that unified Darcy, Forchheimer, and other models. It not only can accurately fit the experimental data but also can describe the nonlinear 
characteristics of seepage in porous media. At present, the Forchheimer model is still the most widely used in the research.

A large number of experimental studies showed that seepage properties of fractured sandstones are influenced by many factors. To this end, $\mathrm{Yu}$ et al. [21] concluded that the seepage ability of different lithological samples is limestone, sandstone, mudstone, and gangue by descending order. Ding et al. [22] investigated the seepage effect of particle diameter distribution in fractured sandstones and concluded that particle diameter has a great effect on the seepage of fractured sandstones under the stress condition, and particle arrangement affects the compressibility of samples. Ma et al. [23] designed seepage experimental devices of fractured sandstones and obtained different porosity under the control of axial displacement in lateral restriction. The seepage effect of the porosity in fractured sandstones under different seepage pressure was studied.

However, as one of the most important properties, gradation characteristics integrated with seepage were rarely studied. The research showed that there are great differences in pore structure of fractured sandstones specimens composed of different particle gradations. Lacey et al. [24] found by CT scan that particle-size distribution has a large influence on local porosity; even the same porosity and high density can be gained by interlaced filling of large and small particle sizes, while single particle size is difficult to achieve that result. Pore structure of the porous medium is an important influential factor of seepage characteristics, so the grading of fractured rock mass has a large effect on seepage characteristics. Therefore, the steady-state tests of coalseam roof sandstones below aquifers were conducted in this paper. Nonlinear characteristics of fractured sandstones seepage under different seepage pressure were discussed. Influences of porosity and grading in nonlinear seepage of fractured sandstones were analyzed.

\section{Sample Preparations and Experimental Scheme}

2.1. Sample Preparations. In this experiment, roof sandstone of typical coalseam under confined aquifer was chosen as the test object. Fractured sandstones were processed in the laboratory. Firstly, large sandstones were broken with a crusher; secondly, the broken rocks were recrushed into smaller particles by using a hammer; finally, rock particles were divided through a series of grading, obtaining fractured sandstone particles with different particle sizes. There are five groups of particle sizes, namely, $0-5 \mathrm{~mm}, 5-10 \mathrm{~mm}$, $10-15 \mathrm{~mm}, 15-20 \mathrm{~mm}, 20-25 \mathrm{~mm}$, as shown in Figure 1.

In geotechnical engineering, the rock particle size in the fractured rock mass is not uniform. Fractured rock mass is the complex macadam containing different particle sizes of the rock particles, namely, the grading macadam. There are three traditional gradation expressions in the seepage experiment of fracture sandstones: $n$ method (Talbot gradation theory), I method (Lin-Xiuxian gradation theory), and nonuniform coefficients [25]. In the actual application, these methods all have certain limitations. The purpose of the

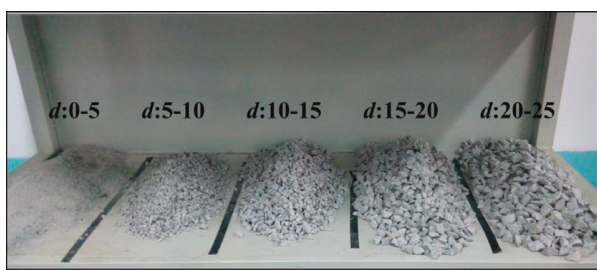

FIgURE 1: Fractured sandstone samples of different particle sizes.

Talbot gradation method is to acquire maximum density of bulk material accumulation, but there are certain defects in describing the particle-size distribution. The premise of $I$ method is the decrease of particle size by $1 / 2$, while it cannot describe the gradation of continuous particle distribution. Nonuniform coefficient method describes the particle size ratio of the specific mass proportion, while other proportions of particles cannot be obtained. To acquire more comprehensive and accurate particle size proportions of fractured rock mass, fractal gradation theory was formulated by gradation parameters of fractured rock mass according to the fractal theory. Current researches show that fractal gradation theory can synthesize the traditional gradation parameter expression and describe the grading characteristics of fractured rock mass more accurately.

According to the fractal theory [26] of fractured rock mass gradation, the calculation method of fractured sandstone gradation is shown in the following equation:

$$
P\left(d_{i}\right)=\frac{d_{\min }^{3-D}-d_{i}^{3-D}}{d_{\min }^{3-D}-d_{\max }^{3-D}} \times 100 \%,
$$

where $D$ is the fractal dimension; $P\left(d_{i}\right)$ is the proportion of gradation samples whose particle size is less than $d_{i}$; and $d_{\max }$ and $d_{\min }$ are the maximum and minimum particle sizes of gradation samples, respectively.

In this experiment, the minimum particle size of sandstones in the gradation samples ranges from 0 to $5 \mathrm{~mm}$. Therefore, $d_{\min }^{3-D} \longrightarrow 0$ and Equation (1) is transformed as

$$
P\left(d_{i}\right)=\left(\frac{d_{i}}{d_{\max }}\right)^{3-D} \times 100 \%,
$$

where fractal dimension $D$ is the experimental planning parameter determined before the experiment and particle size $d_{i}$ of each kind of fractured sandstones is determined in the sample preparation where the maximum particle size $d_{\max }$ is $25 \mathrm{~mm}$. Therefore, mass percent $P\left(d_{i}\right)$ of different particle sizes of fractured sandstones in different fractal dimensional gradation samples is obtained as shown in Table 1. Mass distribution of particle sizes of fractured sandstones is shown in Figure 2.

As can be seen from Table 1 and Figure 2, there are significant differences in the sandstone particle mass proportion with different particle sizes under the different fractal dimensions. When the fractal dimension is small, it has the large proportion of large particle size. With the increasing fractal dimension, the proportion of small particle size increases gradually. In principle, when the fractal 
TABle 1: Proportion of each component particle in different fractal dimensional gradation samples.

\begin{tabular}{|c|c|c|c|c|c|}
\hline \multirow{2}{*}{$D$} & \multicolumn{5}{|c|}{$P\left(d_{i}\right)(\%)$} \\
\hline & $d_{1}=(0-5 \mathrm{~mm})$ & $d_{2}=(5-10 \mathrm{~mm})$ & $d_{3}=(10-15 \mathrm{~mm})$ & $d_{4}=(15-20 \mathrm{~mm})$ & $d_{5}=(20-25 \mathrm{~mm})$ \\
\hline 1.3 & 6.00 & 15.00 & 21.00 & 26.00 & 32.00 \\
\hline 1.7 & 12.00 & 18.00 & 21.00 & 23.00 & 25.00 \\
\hline 2.1 & 23.00 & 20.00 & 19.00 & 19.00 & 18.00 \\
\hline 2.5 & 45.00 & 19.00 & 14.00 & 12.00 & 11.00 \\
\hline 2.9 & 85.00 & 06.00 & 4.00 & 3.00 & 2.00 \\
\hline
\end{tabular}

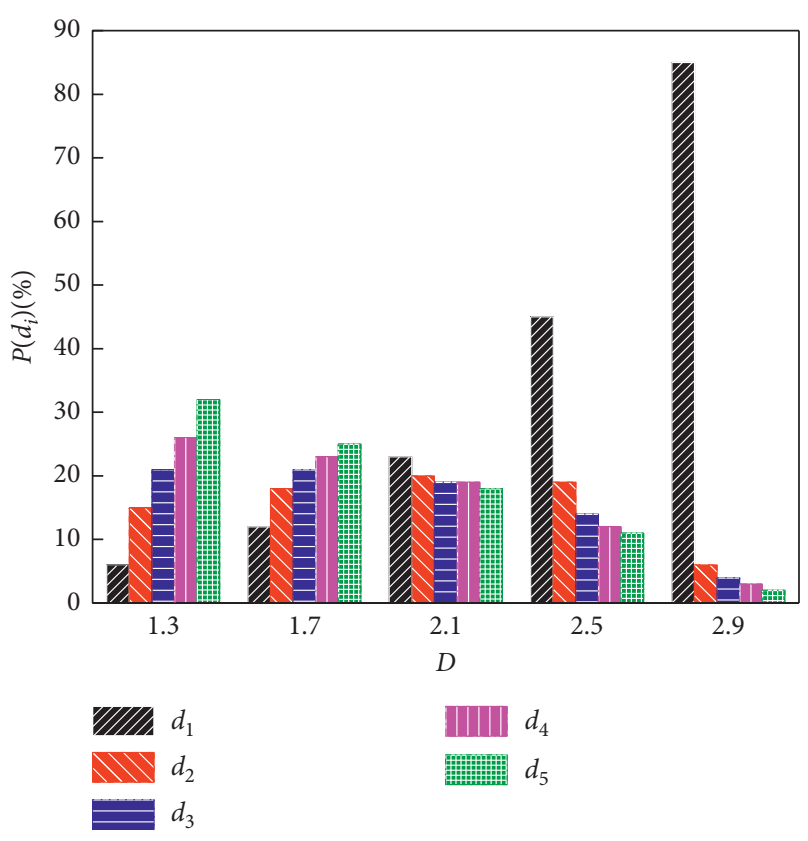

FIGURE 2: Particle mass distribution of different fractal dimensional gradation samples.

dimension is 1.3 , the particle mass proportion whose particle size is less than $5 \mathrm{~mm}$ only accounts for $6.00 \%$ while the particle mass proportion whose particle size is more than $15 \mathrm{~mm}$ accounts only for $58.00 \%$. With the gradual increase of fractal dimension, particle mass proportion whose particle size is below $5 \mathrm{~mm}$ increases gradually. When the fractal dimension is 2.9 , the proportion increases to $85.00 \%$. On the contrary, particle mass proportion whose particle size is more than $15 \mathrm{~mm}$ decreases gradually, only accounting for $5.00 \%$. The main reason of seepage characteristic difference lies in the significant difference of the interior pore structure of different fractal dimensional samples due to the different particle size gradations.

2.2. Experimental System. In this test, the experimental system is a self-developed seepage experimental device, including seepage pressure supply system, axial pressure supply system, seepage system, data collection system, and permeable mixture collection system. As shown in Figure 3(a), the seepage pressure control system (Figure 3(b)) consists of hydraulic power packs, double-action hydraulic cylinders, pumps, controllers, and sensors. Hydraulic oil and water are situated at the upper and bottom of the double-action hydraulic cylinder pistons. Under the action of the pump, hydraulic oil pushes the pistons down slowly to exert static seepage pressure of the seepage system. As the core of the seepage experiment, the osmoscope (Figure 3(c)), includes inflowing poison, the upper waterboard, a seepage cylinder barrel, the bottom waterboard and the foundation. Moreover, intensive uniform throughholes on the upper waterboard are designed to guarantee the water dispersion in the seepage cylinder barrels and the uniform distribution of seepage flow in the upper samples. To ensure the leakproofness of the seepage system, joints between the cylinder barrel and head are sealed by O-type rubber seal. DDL600 electric universal testers are employed in the axial pressure supply system. Data collection device is composed of a fluid flowmeter, a pressure transmitter, a paperless recorder, and a computer.

2.3. Experimental Scheme and Experimental Process. Seepage characteristics of fractured sandstones were analyzed in different gradations and different porosities in this experiment. The experimental scheme is listed as follows.

Scheme 1: Experiments on seepage characteristic of fractured sandstones with different porosities are performed under the condition that fractal dimension $D$ is determined as 2.1, seepage pressure $P$ are $1.0,1.5,2.0,2.5$, are $3.0 \mathrm{MPa}$, and the porosities $\phi$ are $0.10,0.15,2.20,0.25$, and 0.30 respectively.

Scheme 2: Experiments on seepage characteristic of fractured sandstones with different gradations are performed under the condition that the porosity $\phi$ is determined as 0.20 , seepage pressure $P$ are $1.0,1.5,2.0,2.5$, and 3.0 MPa, and fractal dimensions $D$ are $1.3,1.7,2.1,2.5$, and 2.9 respectively.

Taking into account the discreteness of the experimental results, each set of tests was performed 3 times, and the results were averaged.

In the above variables, fractal dimensions $D$ and seepage pressure $P$ have been determined before the experiment, and the porosity is determined before the primary loading of the experiment. The calculation method can be expressed as

$$
\phi=\frac{V_{\mathrm{g}}-V_{\mathrm{r}}}{V_{\mathrm{g}}}=1-\frac{m}{\rho_{0} A\left(h_{0}-h_{i}\right)},
$$

where $V_{\mathrm{g}}$ is sampling volume of fractured sandstones after the primary loading, in $\mathrm{m}^{3}$, and $V_{\mathrm{r}}$ is the volume of the complete sandstones, in $\mathrm{m}^{3}$. 


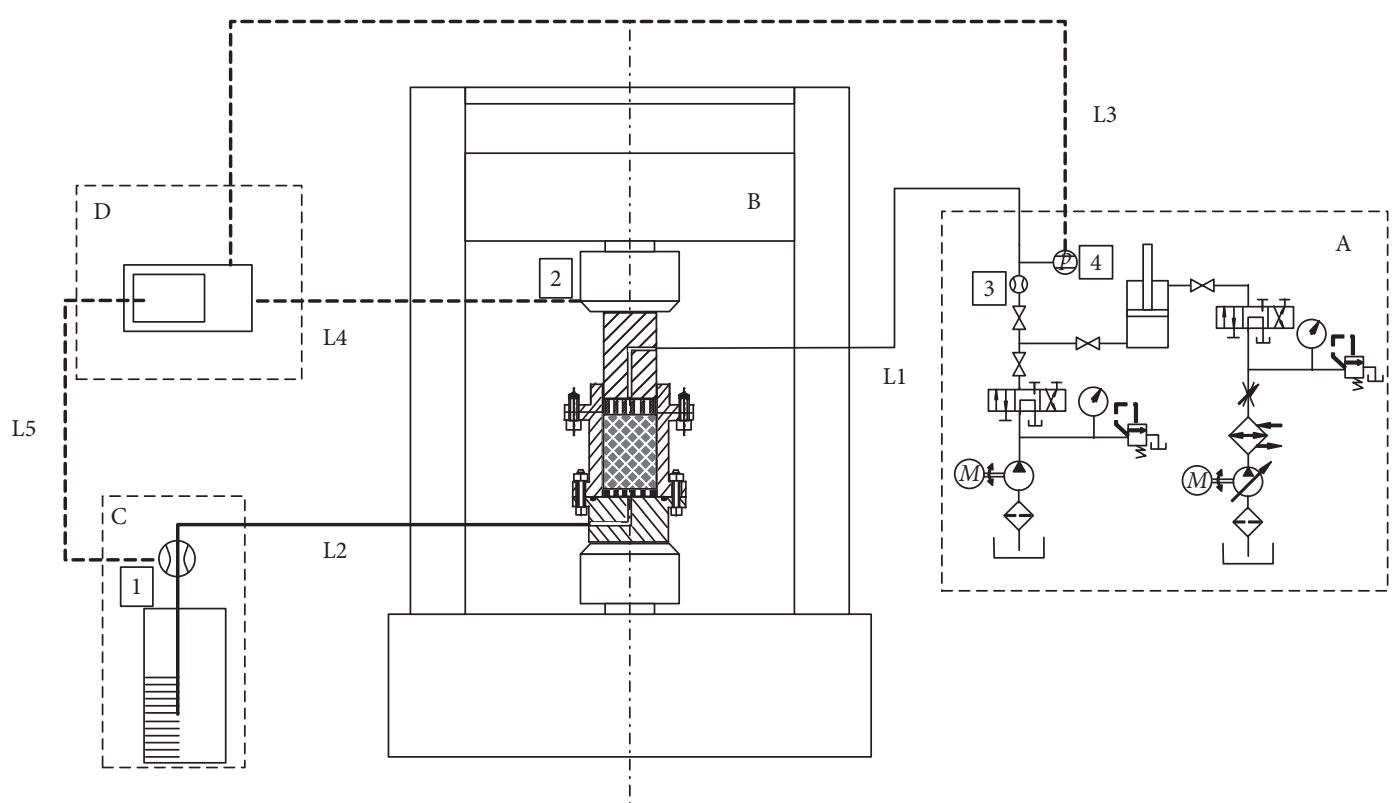

(a)

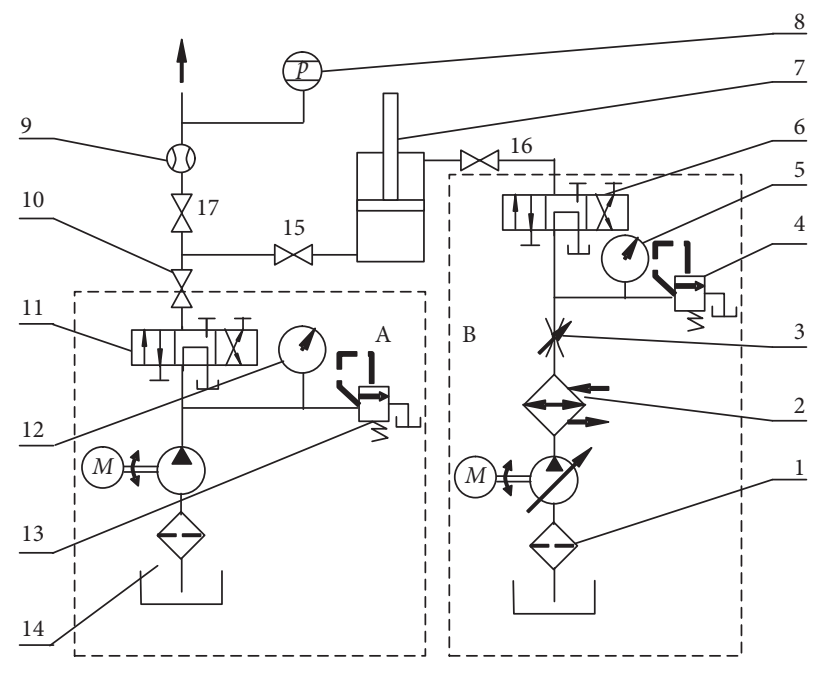

(b)

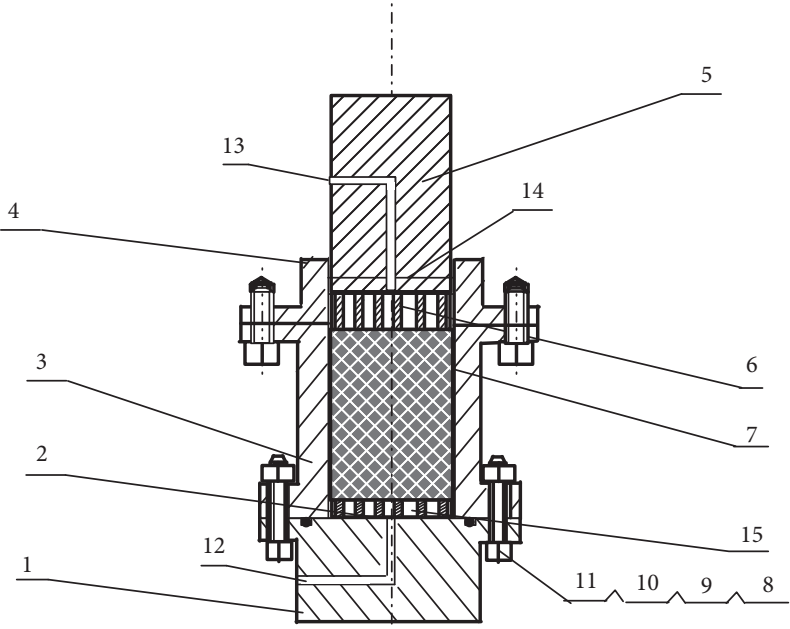

(c)

Figure 3: Seepage experimental system of fractured rock mass. (a) The whole composition of the system. A: seepage pressure supply system; B: axial pressure supply system; C: seepage system; D: data collection system; E: permeable mixture collection system. (b) Supply system of seepage pressure. 1: variable displacement piston pump; 2: cooler; 3: throttle; 4, 13: spill valve; 5, 12: pressure gage; 6, 11: reversing valve; 7: double-action hydraulic cylinders; 8: pressure transmitter; 9: flow transducer; 10: globe valve; 14: fixed displacement piston pump. (c) Osmoscop. 1: baseplate; 2: strainer; 3: cylinder barre; 14: cover plate; 5: squeeze head; 6: upper porous plate; 7: specimen; 8: bolt; 9: nut; 10: flat washer; 11: spring washer; 12: water exit; 13: water entrance; 14: ohne hauch rubber seal; 15: lower porous plate.

Equation (4) is shown as follows:

$$
\begin{aligned}
& V_{\mathrm{g}}=A\left(h_{0}-h_{i}\right), \\
& V_{r}=\frac{m}{\rho_{0}},
\end{aligned}
$$

where $m$ is the mass of fractured sandstones, in $\mathrm{kg} ; \rho_{0}$ is the mass density of sandstones, in $\mathrm{kg} / \mathrm{m}^{3} ; A$ is the crosssectional area of fractured samples, in $\mathrm{m}^{2} ; h_{0}$ is the primary height of fractured sandstones, in $m$; and $h_{i}$ is the primary height of decreasing samples after the initial tester loading, in $m$.
Equation (4) is substituted into Equation (3), and Equation (5) can be obtained as follows:

$$
\phi=1-\frac{m}{\rho_{0} A\left(h_{0}-h_{i}\right)} .
$$

The porosity of grading fractured sandstone samples is determined according to Equation (5).

The specific experimental process is shown as follows: after the installation of the experimental system, the experiment was performed. Firstly, the electric universal tester was started, $0.1 \mathrm{kN}$ was applied by force loading, and the displacement was maintained to ensure the full contact 
between the press ram and osmoscope indenter. The distance between the top of osmoscope indenters and osmoscope bottom was measured to obtain the primary height $h_{0}$ of fractured sandstone samples. Secondly, the pump was opened to fill in the double-acting hydraulic cylinder. When the piston rod rose to the highest position, the piston rod was pushed by hydraulic power pack to move down, and water was squeezed into the permeation loop, so as to realize the sampling permeation. Finally, according to the experimental scheme, axle loading was applied by displacement loading with the setting velocity $v_{0}$ of $0.5 \mathrm{~mm} / \mathrm{min}$. During the experiment, seepage flow was collected in the data collection system with $1 \mathrm{~s}$ collection cycle. When the seepage flow was less than $2 \mathrm{~L} / \mathrm{h}$, the experiment was finished.

\section{Nonlinear Seepage Model of Fractured Sandstones}

Accurate non-Darcy seepage model should be established in order to study the seepage characteristics of fractured rock mass. Recently, Forchheimer model and the BarreeConway model are the most widely used nonDarcy models of porous medium. The Forchheimer model is the empirical model on the basis of the experimental conclusion. Experimental result shows that the assumption of constant Forchheimer factor cannot fully describe the nonlinear characteristics of fluid seepage [27] in fractured rock mass, when describing the nonDarcy flow characteristics in porous media. While Barree-Conway model has the stronger universal applicability, which effectively describes the fluid flowing from the low velocity to high velocity in fractured rock mass overcoming the limitation of Forchheimer model [28]. Therefore, nonlinear seepage model is established based on Barree-Conway model as below:

$$
\frac{\partial P}{\partial h}=\frac{\mu \nu}{k\left(k_{\mathrm{mr}}+\left(\left(1-k_{\mathrm{mr}}\right) /(1+\rho|v| / \mu \tau)\right)\right)},
$$

where $P$ is the seepage pressure, in $\mathrm{MPa}$; $L$ is the sampling height, in $\mathrm{mm}$; $k$ is the permeability ratio, in $\mu \mathrm{m}^{2} ; k_{\mathrm{mr}}$ is the minimum permeability ratio; $\rho$ is the water density, in $1 \mathrm{~g} / \mathrm{cm}^{3}$; $v$ is the seepage velocity, in $\mathrm{mm} / \mathrm{s} ; \mu$ is $1.96 \times 10^{-2} \mathrm{~Pa} \cdot \mathrm{s}$, the kinetic viscosity parameter of the water; $\tau$ is the structural parameter; $1 / \mathrm{mm}$; and $1 / \tau$ is the average pore size of the porous medium. follows:

The minimum permeability ratio can be calculated as

$$
k_{\mathrm{mr}}=\frac{k_{\mathrm{min}}}{k}
$$

where $k_{\min }$ is the minimum permeability ratio of the porous medium.

In Equation (6), the Barree-Conway model degenerates into the Forchheimer model when $k_{\mathrm{mr}}=0$. When $k_{\mathrm{mr}}=1$, the Barree-Conway model is similar to the Darcy model. When $0<\mathrm{k}_{\mathrm{mr}}<1$, the increase of $k_{\mathrm{mr}}$ indicates the weaker nonlinear of seepage.
For specific calculations, the parameters $k_{\min }, k$ and $\tau$ can be obtained by the fitting test data in Equation (6).

\section{Experimental Result and Analysis}

4.1. Nonlinear Seepage Characteristics of Fractured Sandstones. Flow law of water in porous media is closely related to its fracture structure, and its seepage characteristics have an obvious nonlinear characteristic. To specify nonlinear seepage characteristics of fractured sandstones, the relationship curve between the flow velocity $v$ and the time $t$ is shown in Figure 3, where seepage pressure $P=1.0$, or $P=2.0 \mathrm{MPa}$, fractal dimension $D=2.1$, and the porosity $\phi=0.20$. It can be seen that the seepage of fractured sandstones shows the significant nonlinearity. In the primary stage, seepage velocity increases to the larger value suddenly (relating with seepage pressure), and later seepage velocity decreases rapidly. Thereafter, $v_{0}$ fluctuates in the certain range (the average velocity after the stable seepage, $v_{0-1}$, and $v_{0-2}$, in Figure 4 ).

In general, the relationship between the seepage velocity $v$ and the seepage pressure $p$ is used to express seepage characteristics. When the $v$ - $p$ relationship is linear, it indicates the seepage obeys Darcy law; when the $v$ - $p$ relationship is curved, it indicates the seepage is nonlinear. Figure 3 shows that seepage characteristics of fractured rock mass is significantly nonlinear in certain conditions (fixed fractal dimensions, porosity, and seepage pressure). There are many reasons causing this. It is generally believed that the pore flow resistance between fractured rock particles is the most important influential factor. The greater the pore flow resistance of the fluid, the stronger the nonlinear of the seepage. In the seepage of fractured sandstones, the important influential factor of the pore flow resistance is the seepage pressure. With the increasing seepage pressure, pore flow resistance of fractured rock mass increases largely, resulting in the nonlinear variation relationship between the water seepage and seepage pressure.

The variation relationship between seepage velocity $v_{0}$ $\left(v_{0-1}, v_{0-2}\right.$ in Figure 4$)$ and seepage pressure is shown in Figure 5. It can be seen that there is a positive correlation between seepage velocity and seepage pressure, but the relationship is significantly nonlinear. When seepage pressure increases from 1.0 MPa to $2.0 \mathrm{MPa}$, seepage velocity increases from $0.30 \mathrm{~mm} / \mathrm{s}$ to $0.92 \mathrm{~mm} / \mathrm{s}$ linearly whose growth reaches $206.67 \%$. However, when seepage pressure increases from $2.0 \mathrm{MPa}$ to $3.0 \mathrm{MPa}$, seepage velocity increases from $0.92 \mathrm{~mm} / \mathrm{s}$ to $1.10 \mathrm{~mm} / \mathrm{s}$ slowly, whose growth is $19.58 \%$. To further illustrate nonlinear characteristics of seepage velocity varying with seepage pressure, the datum line $l(P)$ (shown in Figure 5) is obtained through the linear fitting of two points, namely $[1.0,0.30],[1.5,0.92]\left(\left[P, v_{0}\right]\right)$. In the comparison of $v$ - $p$ curve and $l(P)$, when $P$ is close to 1.5 $\mathrm{MPa}, v$ - $p$ curve begins to deviate from the datum line and seepage characteristics of fractured sandstones start to be nonlinear. With the increase of seepage pressure, the curvature of $v$ - $p$ curve increases gradually in the same range, the deviation from the datum line rises gradually, and seepage characteristics are more nonlinear. 


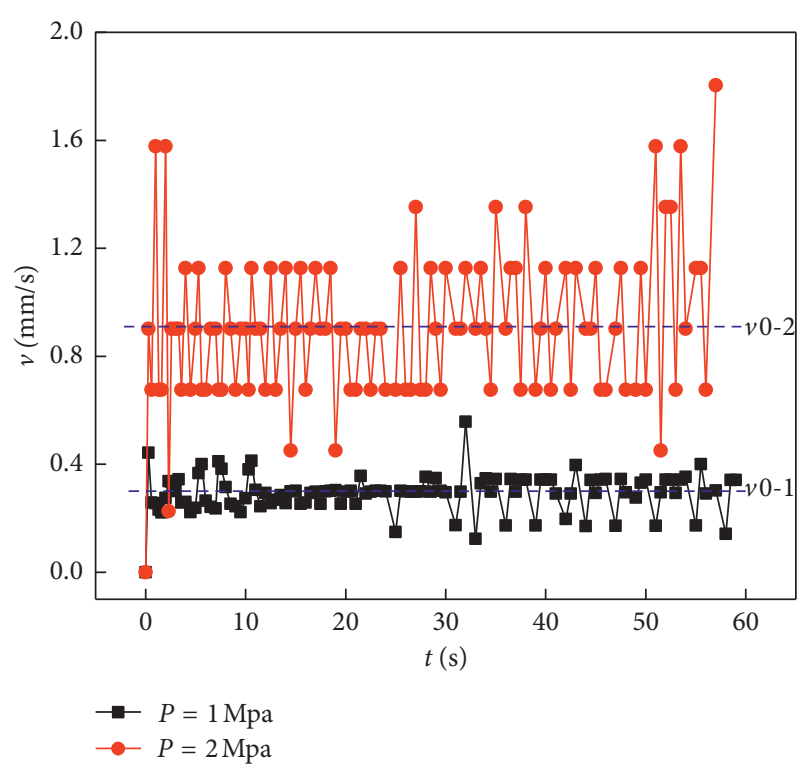

FIgURE 4: Seepage velocity variation curve of fractured sandstones.

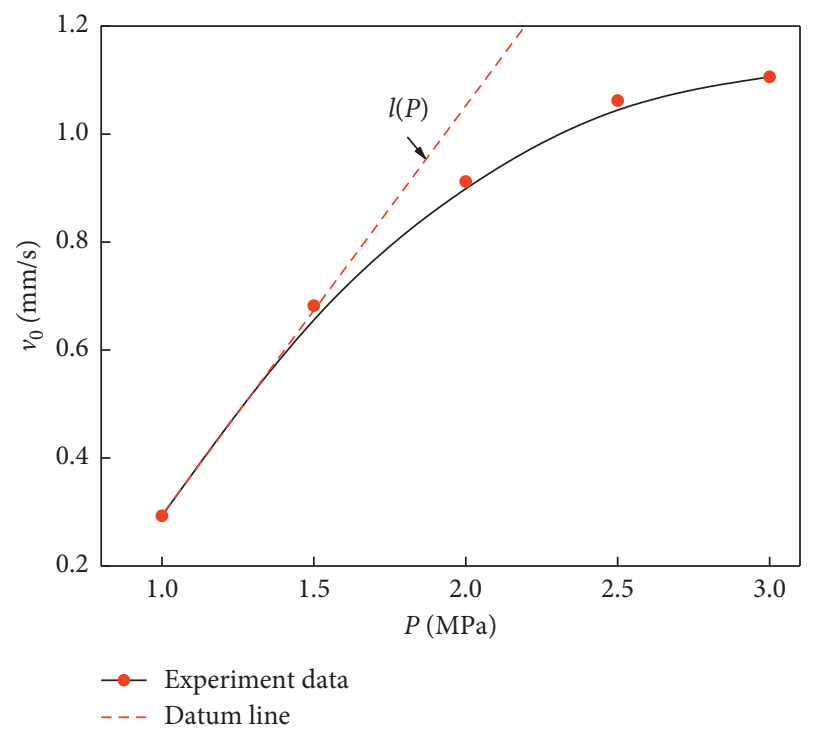

FIGURE 5: The variation curve of seepage velocity with the variation of seepage pressure.

\subsection{The Effect of the Porosity in Seepage Characteristics of Fractured Sandstones}

4.2.1. Variation Characteristics of Seepage Velocity with the Porosity Variation. Variation of seepage velocity $v_{0}$ with the varying seepage pressure is shown in Figure 6, where fractal dimension $D=2.1$ and the porosity $\phi$ are $0.10,0.15,0.20$, 0.25 , and 0.30 , respectively. It can be seen that seepage velocity is consistent with the variation of seepage pressure in different porosity in Figure 6. With the increase of seepage pressure, the curvature of $v-p$ curve increases gradually and nonlinear curve appears greatly in the same range. Comparing different porosity curves, the curvature of the overall $v-p$ curve gradually decreases with the increasing porosity,

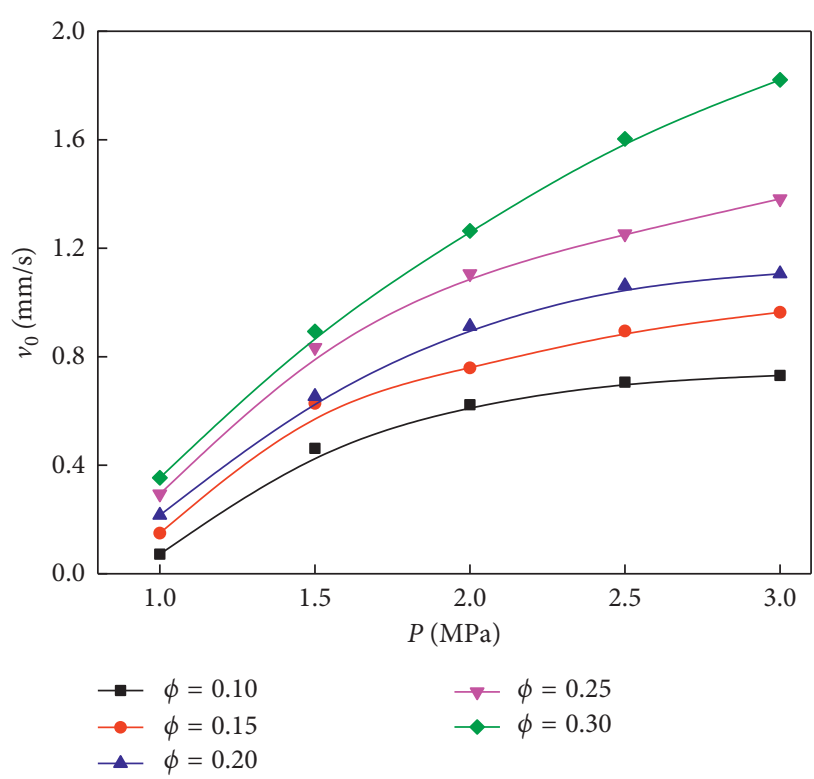

FIGURE 6: The variation curve of seepage velocity with the variation of seepage pressure in different porosities.

namely, the relationship between seepage velocity and seepage pressure changes linearly, indicating that its nonlinear characteristics gradually decrease.

To further explain the effect of the porosity in the seepage characteristics of fractured sandstones, longitudinal comparisons of the test results in Figure 6 were conducted to obtain the variation law of seepage velocity with porosity under different seepage pressure, as shown in Figure 7. With the increase of porosity, the seepage velocity of fractured sandstone increases linearly under different seepage pressure, but there is a significant difference in the increase rate. Specifically, the porosity increases from 0.10 to 0.30 , and increase amplitude of seepage velocity are $0.28 \mathrm{~mm} / \mathrm{s}$, $0.43 \mathrm{~mm} / \mathrm{s}, \quad 0.64 \mathrm{~mm} / \mathrm{s}, \quad 0.90 \mathrm{~mm} / \mathrm{s}$, and $1.09 \mathrm{~mm} / \mathrm{s}$, respectively, under the seepage pressure $(P=1.0-3.0 \mathrm{MPa})$. To ensure the effect of the porosity in the seepage velocity, linear fitting of data is shown in Figure 7.

$$
v_{0}=a \phi+b
$$

where parameter $a$ is the fitting straight slope, which indicates the sensitivity of seepage velocity variation in the porosity; parameter $b$ is the line intercept, which indicates the seepage velocity of fractured sandstones when the porosity is zero.

The parameters $a$ and $b$ are shown in Table 2 under different seepage pressure.

It can be shown that, with the increase of seepage pressure, the parameter $a$ increases gradually in Table 2, indicating the sensitivity of fractured sandstone seepage velocity in the porosity increases gradually. However, the parameter $b$ increases first and decreases with the variation of seepage pressure. When seepage pressure increases from 1.0 to 2.0 , the parameter increases. While seepage pressure increases from 2.0 to 3.0, the parameter decreases gradually. The variation characteristics show that, when the fractured 


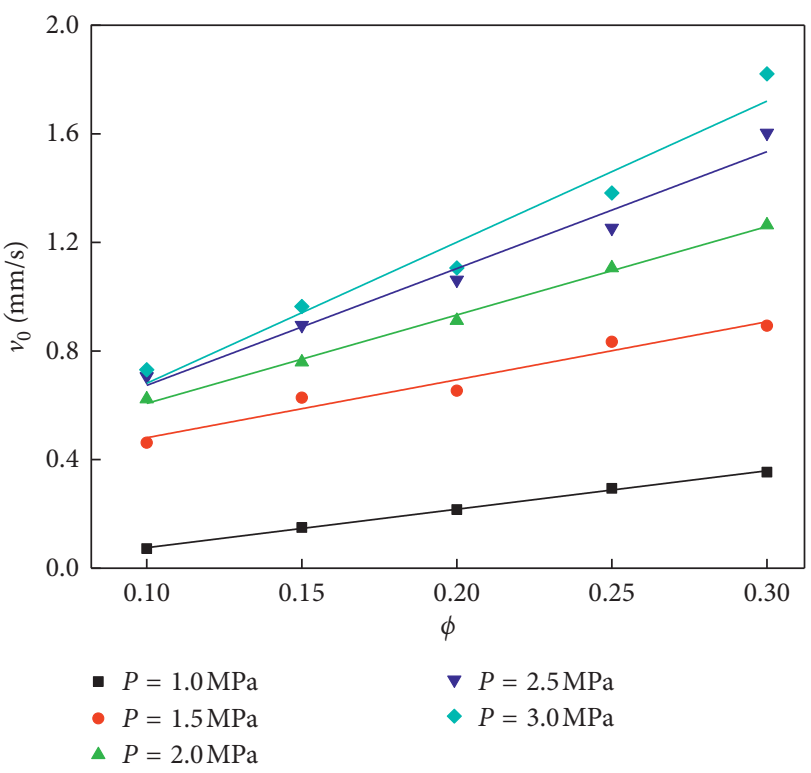

FIGURE 7: The variation curve of seepage velocity with the variation of the porosity under different seepage pressure.

TABLE 2: The characteristic parameters of seepage velocity with the variation of the porosity.

\begin{tabular}{lccc}
\hline$P(\mathrm{MPa})$ & $a$ & $b$ & $R^{2}$ \\
\hline 1.0 & 1.416 & 0.066 & 0.9983 \\
1.5 & 2.136 & 0.267 & 0.9587 \\
2.0 & 3.258 & 0.2812 & 0.9965 \\
2.5 & 4.304 & 0.243 & 0.9749 \\
3.0 & 5.196 & 0.162 & 0.9598 \\
\hline
\end{tabular}

rock mass has a small porosity or it becomes an intact rock sample with a very small amount of seepage, seepage pressure can improve the permeability effectively. But at higher seepage pressure levels, seepage pressure weakens its permeability properties.

4.2.2. Variation Characteristics of Seepage Characteristic Parameters with the Porosity Variation. Through Equation (6) and the experimental data, parameter $k, k_{\min }, k_{\mathrm{mr}}$, and $\tau$ of in the Barree-Conway seepage models were obtained for different porosities, as shown in Table 3.

Figure 8 shows the variation curve of the permeability $k$ and the minimum permeability ratio $k_{\min }$ of fractured sandstones with the variation of the porosity. With the increasing porosity, the permeability and minimum permeability of fractured sandstones increase exponentially, indicating that when the porosity is greater, there has a more sensitive permeability changes.

Within the same porosity range, the increase rate and amplitude of permeability are greater than the minimum seepage amount. Specifically, in the process of increasing the porosity from 0.1 to 0.3 , permeability increases by $22.168 \mu \mathrm{m}^{2}$ and the minimum permeability $k_{\min }$ only increases by $7.380 \mu \mathrm{m}^{2}$, whose difference value increases from $0.130 \mu \mathrm{m}^{2}$ to $14.919 \mu \mathrm{m}^{2}$.
TABLE 3: Barree-conway seepage model parameters of fractured sandstones with different porosities.

\begin{tabular}{lcccc}
\hline$\Phi$ & $k\left(\mu \mathrm{m}^{2}\right)$ & $k_{\min }\left(\mu \mathrm{m}^{2}\right)$ & $k_{\mathrm{mr}}$ & $\tau(1 / \mathrm{mm})$ \\
\hline 0.10 & 0.132 & 0.00170 & 0.013 & 2.762 \\
0.15 & 1.625 & 0.139 & 0.086 & 1.595 \\
0.20 & 6.359 & 0.795 & 0.125 & 0.895 \\
0.25 & 12.900 & 2.941 & 0.228 & 0.615 \\
0.30 & 22.300 & 7.381 & 0.331 & 0.526 \\
\hline
\end{tabular}

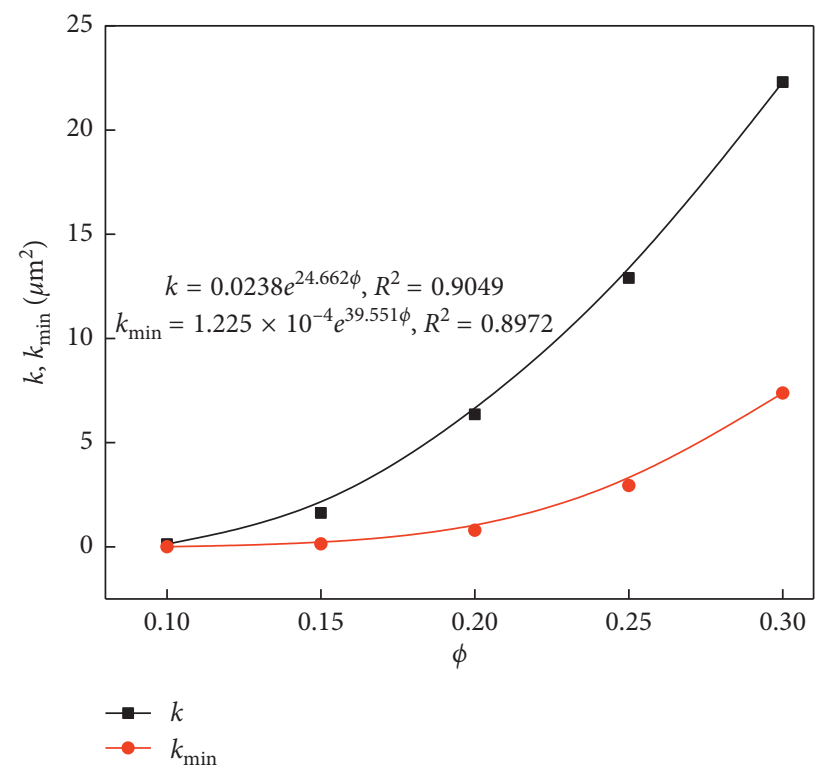

FIGURE 8: The variation of the permeability $k$ and the minimum permeability ratio $k_{\min }$ with the variation of the porosity.

Figure 9 shows the variation curve of the minimum permeability $k_{\mathrm{mr}}$ and average aperture $1 / \tau$ of fractured sandstones with the variation of the porosity. With the increase of the porosity, the minimum permeability and average pore size of fractured sandstones increase linearly, namely, when the porosity increases from 0.10 to 0.30 , the minimum permeability increases from 0.013 to 0.331 by 24.50 times and the average pore size increases from $0.358 \mathrm{~mm}$ to $1.903 \mathrm{~mm}$ by 4.32 times. The porosity of fractured sandstones is the ratio between the sum of pore space volume and sandstone sampling volume. When the porosity becomes greater, there is a larger average pore size and less resistance for water flowing through the hole. Therefore, seepage of fractured sandstones is less nonlinear, which means if the nonlinear minimum permeability $k_{\mathrm{mr}}$ is greater, the seepage of fractured sandstones is more close to that of Dacy model.

\subsection{The Effect of Gradation in Seepage Characteristics of Fractured Sandstones}

4.3.1. Variation Characteristics of Seepage Velocity with the Variation of Fractal Dimensions. Seepage experiment on fractured sandstones with different dimensions and gradations was carried out where the porosity $\phi$ is 0.20 , so that the 


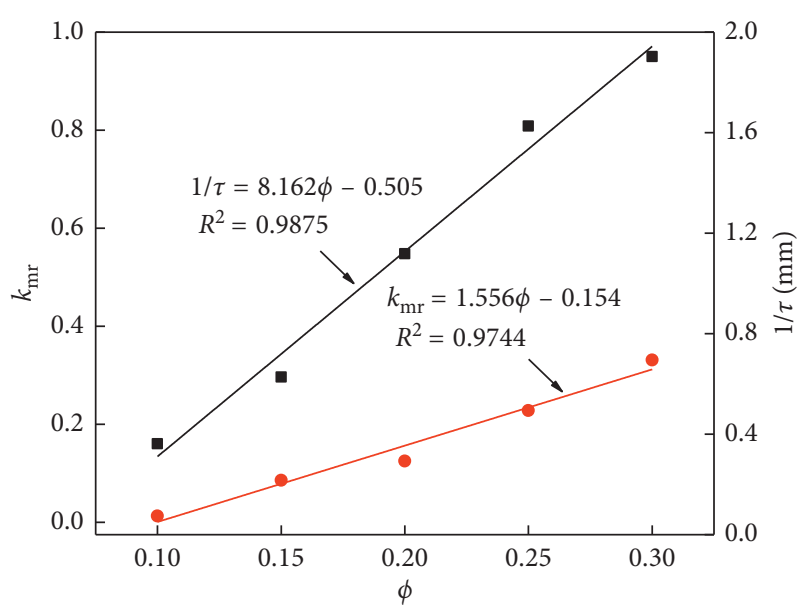

FIgURE 9: The variation of the minimum permeability ratio $k_{\mathrm{mr}}$ and average aperture $1 / \tau$ with the variation of the porosity.

seepage velocity variation of sandstones with different fractal dimensions can be reached as shown in Figure 10. It can be obtained that with different fractal dimensions, seepage velocity is almost the same with the variation of seepage pressure. With the increase of seepage pressure, the slope of $v-p$ curve decreases gradually in the same range. In comparison with other curves, with the increase of fractal dimensions, the curvature of the whole $v$ - $p$ curve increases gradually, which means its nonlinearity strengthens gradually.

Similarly, in order to further analyze the influence of fractal dimension on the seepage velocity of fractured sandstone, the variation law of seepage velocity with fractal dimension under different seepage pressure is given in Figure 11. Under different seepage pressure, as the fractal dimension increases, the seepage velocity gradually decreases and changes linearly. Specifically, when the fractal dimension increases from 1.3 to 2.9 , the percolation velocity decreases. The amplitudes were $0.5 \mathrm{~mm} / \mathrm{s}, 0.55 \mathrm{~mm} / \mathrm{s}, 0.61 \mathrm{~mm} / \mathrm{s}$, $0.70 \mathrm{~mm} / \mathrm{s}$, and $0.81 \mathrm{~mm} / \mathrm{s}$, respectively. Therefore, there is an opposite effect of fractal dimensions in the seepage compared with that of the porosity. Table 1 illustrates that with the increasing fractal dimensions, particle percent of small pore size sandstones increases gradually. Particle interaction of fractured sandstone samples becomes denser, and seepage resistance increases gradually. Thus, the seepage velocity decreases gradually and becomes more nonlinear.

Similarly, to further analyze the influence of fractal dimensions on seepage velocity, the fitting equation between seepage velocity and fractal dimensions is as follows:

$$
v_{0}=c D+d,
$$

where parameter $c$ is the fitting slope, which means the sensitivity of seepage velocity to the decrease of fractal dimension; and parameter $d$ is the fitting slope. As there is no physical significance when the fractal dimension is zero, it is unnecessary to analyze the variation of $d$.

The parameters $c$ and $d$ are given under different seepage pressure in Table 4.

It can be obtained that, with the increase of seepage pressure, the absolute value of parameter $c$ increases

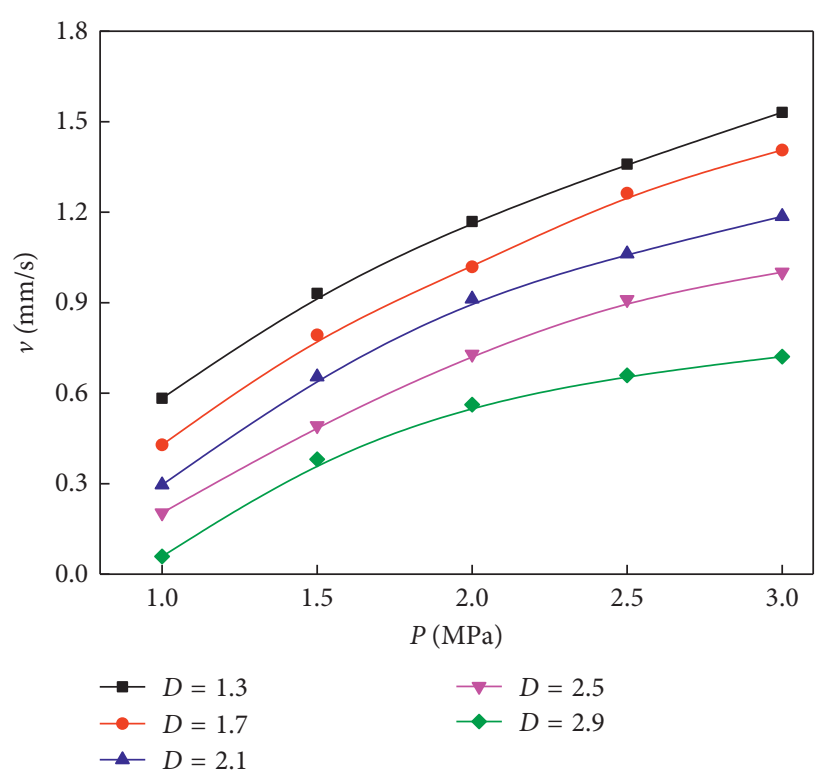

FIGURE 10: The variation curve of seepage velocity with the variation of seepage pressure in different fractal dimensions.

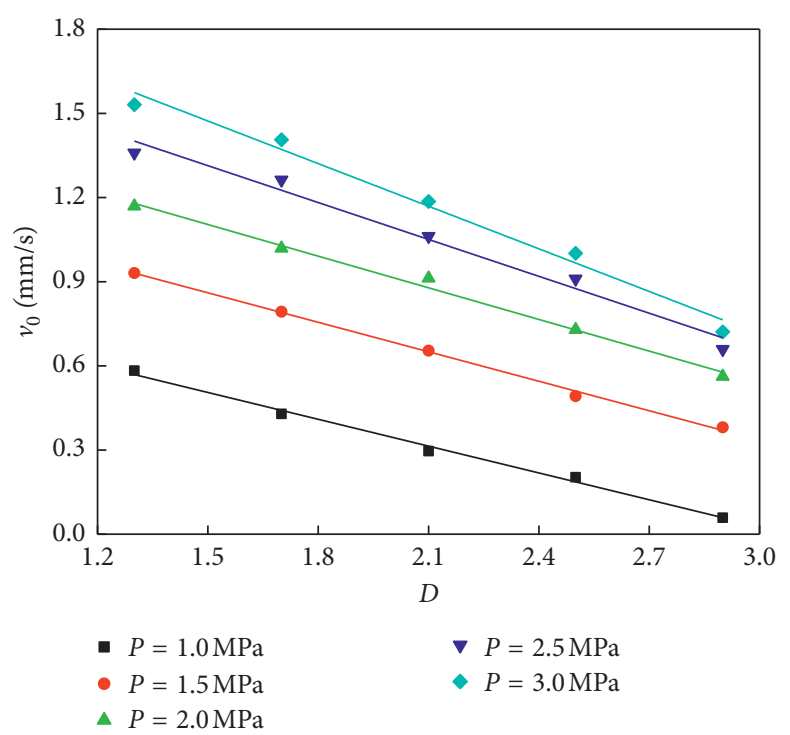

FIGURE 11: The variation curve of seepage velocity with the variation of fractal dimension under different seepage pressure.

TABLE 4: Characteristic parameters of seepage velocity with the variation of fractal dimensions.

\begin{tabular}{lccc}
\hline$P(\mathrm{MPa})$ & $-c$ & $d$ & $R^{2}$ \\
\hline 1.0 & 0.319 & 0.983 & 0.9942 \\
1.5 & 0.350 & 1.386 & 0.9976 \\
2.0 & 0.376 & 1.668 & 0.9931 \\
2.5 & 0.438 & 1.9709 & 0.9803 \\
3.0 & 0.506 & 2.2321 & 0.9847 \\
\hline
\end{tabular}

gradually, which means seepage velocity increases with the increasing seepage pressure and the decreasing fractal dimension. It also indicates that with the increase of seepage 
pressure, the seepage velocity enhances gradually with the decrease of fractal dimension sensibility.

\subsubsection{Variation Characteristics of Seepage Characteristic} Parameters with Variation of Fractal Dimensions. According to the experimental result, Barree-Conway seepage model parameters $k, k_{\min }, k_{\mathrm{mr}}$, and $\tau$ are calculated with Equation (6), as shown in Table 5.

According to Table 5, the variation curve of permeability $k$ and and the minimum permeability ratio $k_{\min }$ with the variation of fractal dimension are obtained in Figure 12. With the increase of fractal dimensions, the permeability and the minimum permeability ratio reduce exponentially. The variation amplitude and velocity of the above two parameters decrease gradually, indicating that the sensitivity of seepage variation reduces gradually. Compared the fitting formula of two parameters with fractal dimensions, in the same range of fractal dimensions, decrease amplitude of the permeability is more than the minimum permeability amplitude. However, the decrease rate is less than that of the minimum permeability (the comparison of exponential parameters). In detail, fractal dimension increases from 1.3 to 2.9 . Permeability and minimum permeability ratio are $16.806 \mu \mathrm{m}^{2}$ and $7.513 \mu \mathrm{m}^{2}$, and difference values decrease from $11.086 \mu \mathrm{m}^{2}$ to $1.793 \mu \mathrm{m}^{2}$.

Figure 13 shows the variation curve of the minimum permeability ratio $k_{\mathrm{mr}}$ and average aperture $1 / \tau$ with the variation of fractal dimensions. With the increase of fractal dimensions, the minimum permeability ratio and average aperture decrease linearly. To be specific, when fractal dimension increases from 1.3 to 2.9 , the minimum permeability ratio decreases from 0.405 to 0.018 in the extent of $95.56 \%$. The average pore size decreases from $2.681 \mathrm{~mm}$ to $0.861 \mathrm{~mm}$ in the extent of $67.89 \%$. Fractal dimensions of gradation are the important parameters in describing particle-size distribution of fractured rock mass. When the fractal dimensions of gradation are greater, there is a higher proportion of small particle samples, thus particle filling becomes denser with smaller average pore size. When seepage resistance is greater, there are many nonlinear characteristics. With the increase of the minimum permeability ratio $k_{\mathrm{mr}}$ of characteristic indexes, the seepage of fractured sandstones is more close to that of the Forchheimer model.

\section{Conclusion}

Through a self-developed seepage testing system, experiments on seepage characteristic were performed by sandstones of the coalseam roof. Nonlinear seepage characteristics and particle gradation effect of fractured rock mass under different seepage pressure were studied in this paper. The main research conclusions are concluded as follows:

(1) Based on the Barree-Conway theory, a nonlinear seepage model and parameter calculation method of fractured sandstones was established. Experimental results showed that the Barree-Conway model could
TABLE 5: Barree-Conway seepage model parameters of fractured sandstones in different fractal dimensions.

\begin{tabular}{lcccc}
\hline$D$ & $k\left(\mu \mathrm{m}^{2}\right)$ & $k_{\min }\left(\mu \mathrm{m}^{2}\right)$ & $k_{\mathrm{mr}}$ & $\tau(1 / \mathrm{mm})$ \\
\hline 1.3 & 18.632 & 7.546 & 0.405 & 0.373 \\
1.7 & 10.426 & 3.034 & 0.291 & 0.462 \\
2.1 & 6.359 & 0.674 & 0.106 & 0.502 \\
2.5 & 3.281 & 0.167 & 0.051 & 0.631 \\
2.9 & 1.826 & 0.033 & 0.018 & 1.161 \\
\hline
\end{tabular}

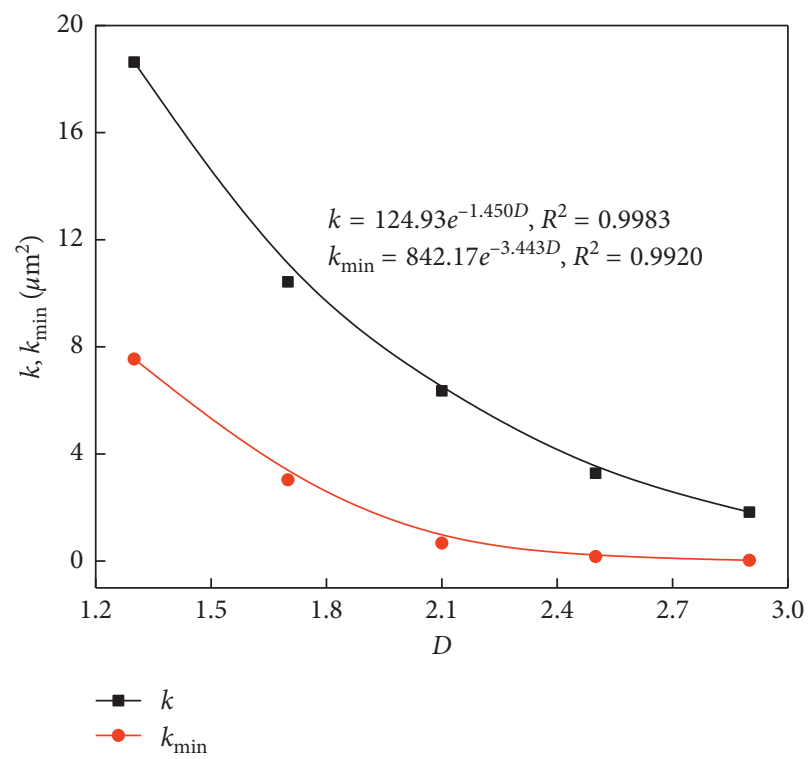

FIGURE 12: The variation of permeability $k$ and the minimum permeability ratio $k_{\min }$ with the variation of fractal dimension.

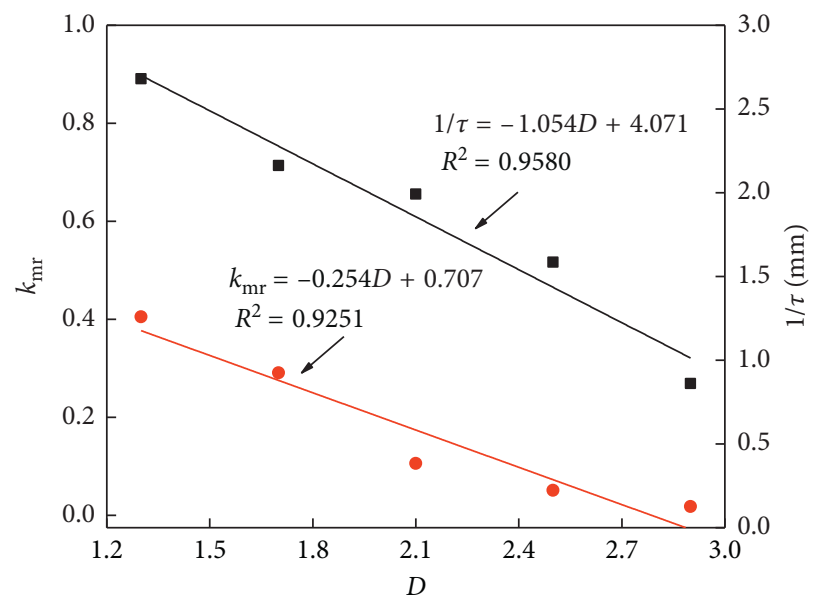

FIGURE 13: The variation of the minimum permeability ratio $k_{\mathrm{mr}}$ and average aperture $1 / \tau$ with the variation of fractal dimensions.

clearly describe seepage characteristics of fractured sandstones.

(2) The nonlinear characteristics of seepage flow in fractured sandstone were significantly affected by the seepage pressure. Under certain porosity and gradation conditions, with the increase of seepage 
pressure, the nonlinearity of the seepage in fractured sandstones increases.

(3) Permeability $k$ and minimum permeation ratio $k_{\mathrm{mr}}$ were positively correlated with porosity, which can be characterized (by the function); the nonlinearity of seepage in fractured rock mass was negatively correlated with porosity: namely, with the increase of the porosity in fractured sandstones, it had the weaker linearity of seepage. Thus, theoretical explanation of seepage characteristics of fractured sandstones was closer to that of the Darcy model.

(4) With the increase of grading fractal dimension, average pore size of fractured rock mass reduced, and permeability $k$ and the minimum permeability ratio $k_{\text {mr }}$ became smaller. It indicated that with the increase of grading fractal dimension in fractured rock mass, the permeability decreased, while the nonlinear seepage increased. Thus, theoretical explanation of seepage characteristics of fractured sandstones was more close to that of the Forchheimer model.

\section{Data Availability}

The data used to support the findings of this study are available from the corresponding author upon request.

\section{Conflicts of Interest}

The authors declare that there are no conflicts of interest regarding the publication of this paper.

\section{Acknowledgments}

This work was financially supported by School Basic Scientific Research Operating Expenses Project (No. 2017XKQY097).

\section{References}

[1] R. Zhang, Z. Jiang, H. Zhou, C. Yang, and S. Xiao, "Groundwater outbursts from faults above a confined aquifer in the coal mining," Natural Hazards, vol. 71, no. 3, pp. 1861-1872, 2014.

[2] N. R. Backeberg, C. D. Rowe, and N. Barshi, "Alterationweakening leading to localized deformation in a damage aureole adjacent to a dormant shear zone," Journal of Structural Geology, vol. 90, pp. 144-156, 2016.

[3] H. Mansurbeg, S. Morad, A. Salem et al., "Diagenesis and reservoir quality evolution of palaeocene deep-water, marine sandstones, the shetland-faroes Basin, British continental shelf," Marine \& Petroleum Geology, vol. 25, no. 6, pp. 514543, 2008.

[4] P. M. Adler and J. F. Thovert, Fractures and Fracture Networks, Springer, Berlin, Germany, 1999.

[5] D. Ma, Q. Li, M. R. Hall, and Y. Wu, "Experimental investigation of stress rate and grain size on gas seepage characteristics of granular coal," Energies, vol. 10, no. 4, p. 527, 2017.

[6] D. Ma, X. Cai, Z. L. Zhou, and X. B. Li, "Experimental investigationon hydraulic properties of granular sandstone andmudstone mixtures," Geofluids, vol. 2018, Article ID 9216578, 13 pages, 2018.

[7] J. Chen, L. I. Xinwen, and W. Zhao, "Study on piping leakage mechanism," Journal of Hydraulic Engineering, vol. 31, no. 9, pp. 0048-0055, 2000.

[8] S. R. Feng, H. B. Zhao, Z. M. Jiang et al., "Experimental study on seepage failure characteristics of broken rock mass in dam foundation at left bank of Xiangjiaba hydropower project," Chinese Journal of Geotechnical Engineering, vol. 34, no. 4, pp. 600-605, 2012.

[9] B. Yang, G. Yang, and Y. E. Gui, "Quality of water under dam foundation and seepage characteristics," Journal of Hehai University, vol. 29, no. 2, pp. 91-95, 2001.

[10] D. Swartzendruber, "Non-Darcy flow behavior in liquidsaturated porous media," Journal of Geophysical Research, vol. 67, no. 13, pp. 5205-5213, 1962.

[11] I. Engelhardt and S. Finsterle, "Thermal-hydraulic experiments with bentonite/crushed rock mixtures and estimation of effective parameters by inverse modeling," Applied Clay Science, vol. 23, no. 1, pp. 111-120, 2003.

[12] X. Miao, S. Li, Z. Chen et al., "Experimental study of seepage properties of broken sandstone under different porosities," Transport in Porous Media, vol. 86, no. 3, pp. 805-814, 2011.

[13] B. Li, "Relationships for non-darcy flow in rockfill," Journal of Hydraulic Engineering, vol. 124, no. 2, pp. 206-212, 1998.

[14] S. Q. Yang, H. W. Jing, Y. H. Huang, P. G. Ranjith, and Y. Y. Jiao, "Fracture mechanical behavior of red sandstone containing a single fissure and two parallel fissures after exposure to different high temperature treatments," Journal of Structural Geology, vol. 69, pp. 245-264, 2014.

[15] S. Whitaker, "The forchheimer equation: a theoretical development," Transport in Porous Media, vol. 25, no. 1, pp. 27-61, 1996.

[16] Z. Zhou, X. Cai, D. Ma, L. Chen, S. Wang, and L. Tan, "Dynamic tensile properties of sandstone subjected to wetting and drying cycles," Construction and Building Materials, vol. 182, pp. 215-232, 2018.

[17] H. Huang and J. A. Ayoub, "Applicability of the forchheimerequation for nonarcy flow in porous media," in Proceedingsof SPE Annual Technical Conference and Exhibition, vol. 13, no. 1, pp. 112-1221, New Orleans, LA, USA, September 2006.

[18] Z. Zeng and R. Grigg, "A criterion for non-darcy flow in porous media," Transport in Porous Media, vol. 63, no. 1, pp. 57-69, 2006.

[19] G. S. Beavers and E. M. Sparrow, "Non-darcy flow through fibrous porous media," Journal of Applied Mechanics, vol. 36, no. 4, p. 711, 1969.

[20] R. D. Barree and M. W. Conway, "Beyond beta factors: a complete model for darcy, forchheimer, and transforchheimer flow in porous media," Journal of Petroleum Technology, vol. 57, no. 8, p. 73, 2004.

[21] B. Yu, Z. Chen, Q. Ding, and L. Wang, "Non-darcy flow seepage characteristics of saturated broken rocks under compression with lateral constraint," International Journal of Mining Science and Technology, vol. 26, no. 6, pp. 1145-1151, 2016.

[22] D. X. Ding, G. Y. Li, W. P. Xu et al., "Regularities for saturated water seepage in loose fragmented medium," Yantu Gongcheng Xuebao/Chinese Journal of Geotechnical Engineering, vol. 32, no. 2, pp. 180-184, 2010.

[23] D. Ma, Z. L. Zhou, J. Y. Wu, Q. Li, and H. Bai, "Grain size distribution effect on the hydraulic properties of disintegrated coal mixtures," Energies, vol. 10, no. 5, p. 612, 2017. 
[24] M. Lacey, C. Hollis, M. Oostrom, and N. Shokri, "Effects of pore and grain size on water and polymer flooding in micromodels," Energy and Fuels, vol. 31, no. 9, pp. 9026-9034, 2017.

[25] R. Yang, Z. Xu, C. Zhang et al., "Fractal gradation theory of asphalt mixture," Journal of Tongji University, vol. 12, no. 12, p. 36,2008

[26] S. Zhu, S. D. Deng, Z. Y. Ning et al., "Gradation design method for rockfill materials based on fractal theory," Chinese Journal of Geotechnical Engineering, vol. 39, no. 6, pp. 11511155, 2017.

[27] M. A. Meraj, S. A. Shehzad, T. Hayat, F. M. Abbasi, and A. Alsaedi, "Darcy-forchheimer flow of variable conductivity jeffrey liquid with cattaneo-christov heat flux theory," Applied Mathematics and Mechanics, vol. 38, no. 4, pp. 557-566, 2017.

[28] J. Petrasch, F. Meier, H. Friess, and A. Steinfeld, “Tomography based determination of permeability, dupuit-forchheimer coefficient, and interfacial heat transfer coefficient in reticulate porous ceramics," International Journal of Heat \& Fluid Flow, vol. 29, no. 1, pp. 315-326, 2008. 


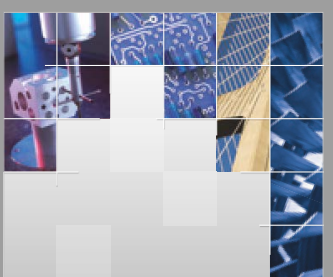

\section{Enfincering}
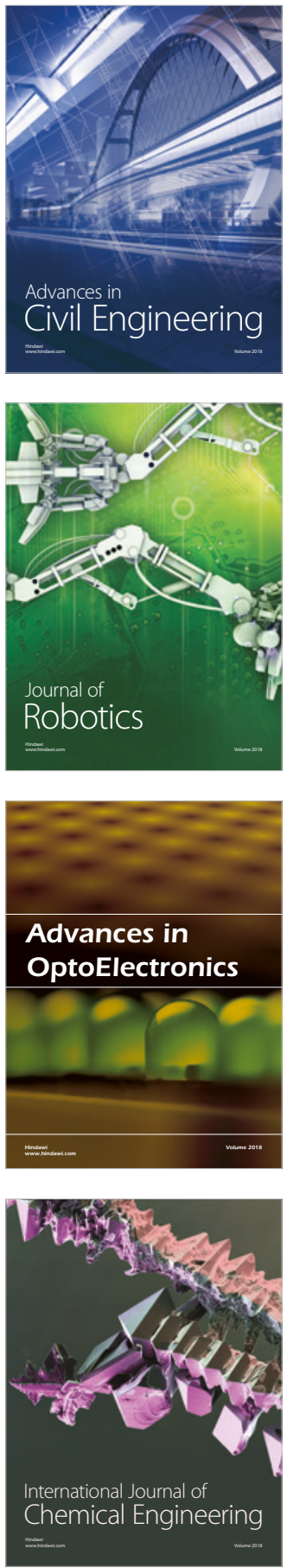

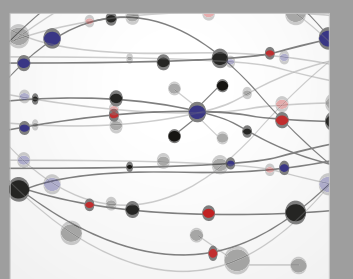

\section{Rotating \\ Machinery}

The Scientific World Journal

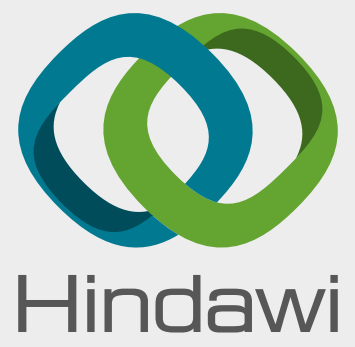

Submit your manuscripts at

www.hindawi.com
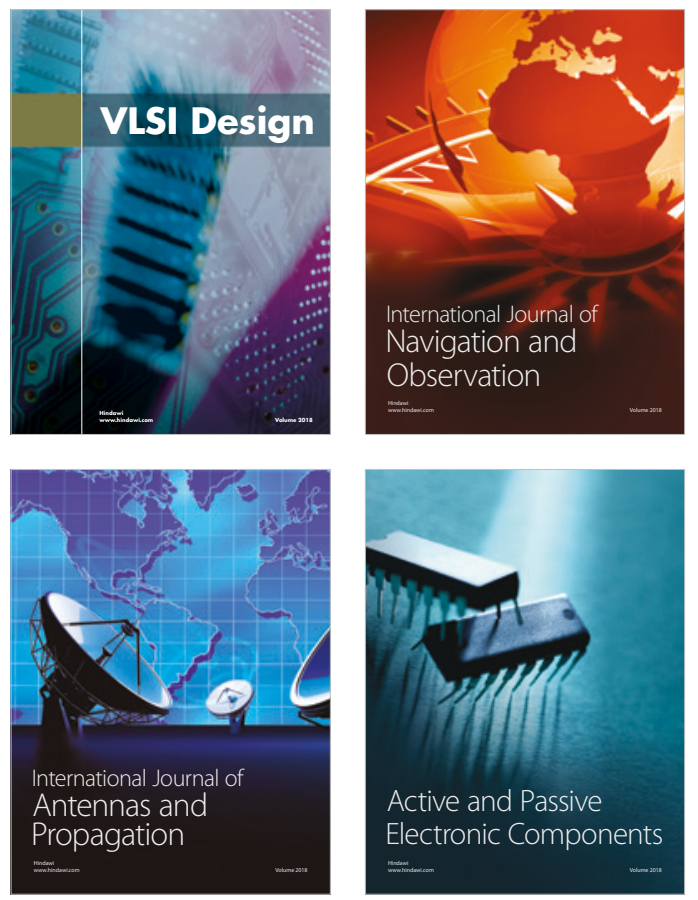
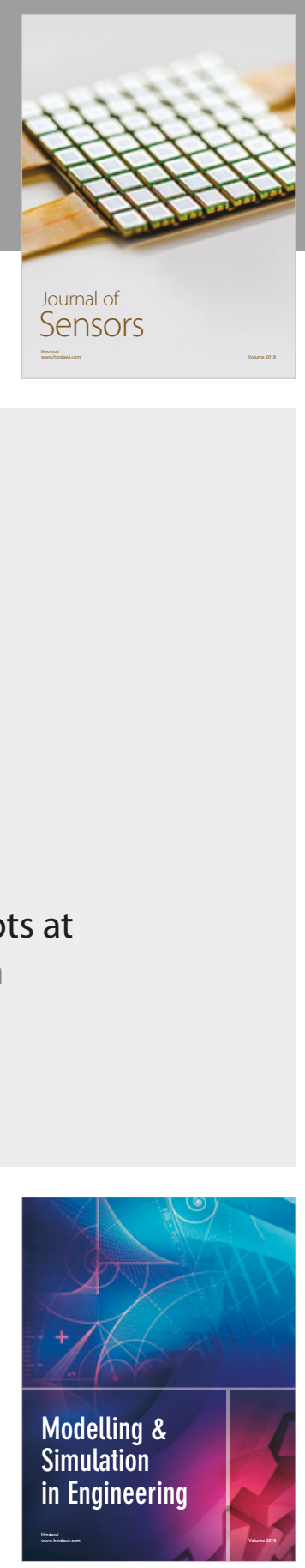

\section{Advances \\ Multimedia}
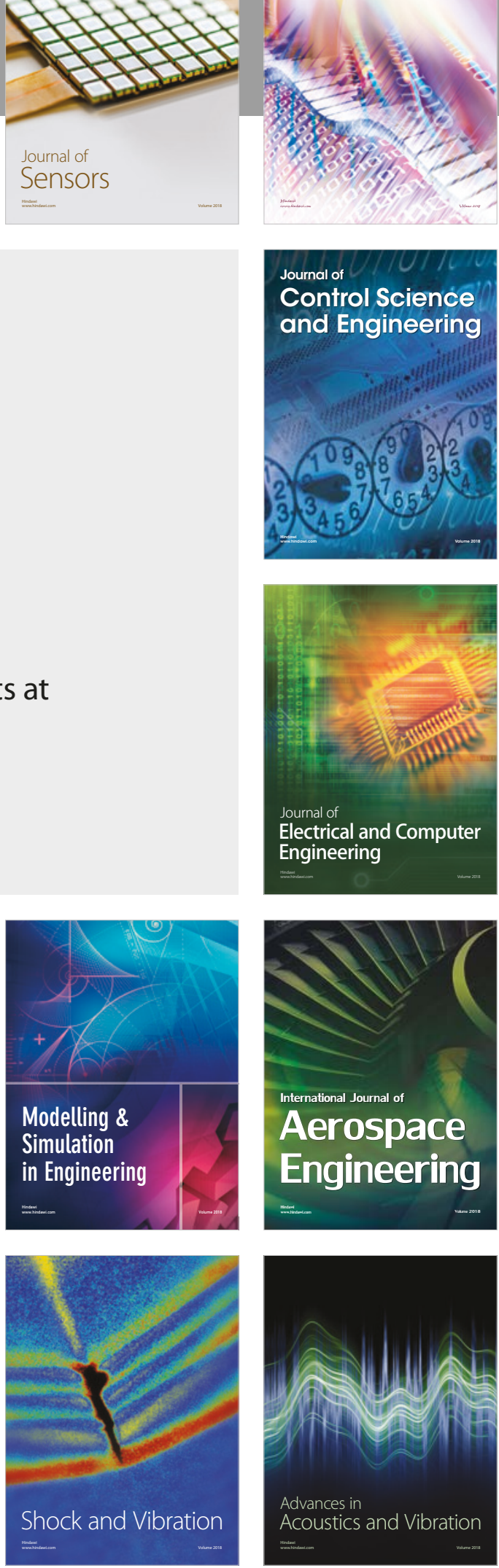